\title{
La cooperación descentralizada y las estructuras institucionales para la internacionalización de los gobiernos no centrales: Los casos de Bogotá y Ciudad de México
}

\section{A cooperação descentralizada e as estruturas institucionais para a internacionalização dos governos não centrais: os casos de Bogotá e da Cidade do México}

Denisse A. Grandas Estepa'

3. Doctoranda en Relaciones Internacionales de la Universidad Nacional de la

Plata, Argentina, Magister en Desarrollo y Ayuda Internacional de la Universidad Complutense de Madrid, España, Internacionalista de la Universidad de Bogotá Jorge Tadeo Lozano, Colombia.

Actualmente, se desempeña como Decana de la Facultad de Relaciones Internacionales, Estrategia y Seguridad de la Sede Campus Nueva Granada de la Universidad Militar Nueva Granada, Colombia. Cajicá/Colombia. ORCID: 0000-0002-5563-3994 (1D)

\begin{abstract}
RESUMEN
La cooperación descentralizada es una modalidad a través de la cual los Gobiernos No Centrales (GNC) han promovido sus asuntos internacionales y de cooperación. Por esta razón, muchos de estos gobiernos han impulsado la institucionalización a través de la vinculación de áreas dedicadas a tal fin y la definición de políticas y estrategias como medios para legitimar las relaciones con sus socios internacionales. Bajo este contexto, el artículo tiene como objetivo examinar los factores explicativos de los procesos de institucionalización de la cooperación descentralizada de Bogotá y Ciudad de México, con el propósito de identificar similitudes, diferencias, tendencias y oportunidades más representativas. Para lograr este propósito, se revisaron fuentes primarias y secundarias y se realizaron entrevistas a funcionarios de los gobiernos de Bogotá y Ciudad de México entre el 2016 y 2017. El planteamiento principal considera que la tendencia a institucionalizar estos procesos viene de la mano de prácticas comunes y patrones preestablecidos que ayudan a mantener y legitimar los campos organizacionales dedicados a los asuntos internacionales.
\end{abstract}

Palabras clave: cooperación descentralizada; Colombia; México; Bogotá; Ciudad de México; institucionalización.

RESUMO

A cooperação descentralizada é uma modalidade através da qual os Governos Não Centrais (GNC) promovem os seus assuntos internacionais e de cooperação. Por esta razão, muitos dos governos têm estimulado a institucionalização através da vinculação de áreas dedicadas a esse fim e a definição de politicas e estratégias como meios para legitimar as relações com os seus sócios internacionais. Neste contexto, o artigo tem como objetivo examinar os fatores explicativos dos processos de institucionalização da cooperação descentralizada 
de Bogotá e da Cidade do México, com o propósito de identificar semelhanças, diferenças, tendências e oportunidades mais representativas. Para alcançar este propósito, fez-se uma revisão de fontes primárias e secundárias e realizaram-se entrevistas a funcionários dos governos de Bogotá e da Cidade do México entre 2016 e 2017. A proposta principal consiste em que a tendência a institucionalizar estes processos vem associada a práticas comuns e padrões pré-estabelecidos que ajudam a manter e legitimar os campos organizacionais dedicados aos assuntos internacionais.

Palavras-chave: cooperação descentralizada; Colômbia; México; Bogotá; Cidade do México; institucionalização

Introducción

La globalización es un fenómeno que empieza a hacer presencia desde la segunda mitad del siglo XX y cuyo fundamento se orienta hacia la promoción de las economías de mercado, el intercambio fluido de bienes y servicios, la reducción progresiva de las fronteras (LASCURAIN; LÓPEZ, 2013) y la aparición de nuevos actores que interactúan en el sistema internacional, para llevar a cabo relaciones de tipo económico, comercial y político.

Como parte de esta dinámica, los gobiernos no centrales $(\mathrm{GNC})^{2}$, han empezado a jugar un rol fundamental en la gestión y establecimiento de relaciones de cooperación internacional, con el propósito de aumentar su presencia internacional y responder a los desafíos del desarrollo.

Por esta razón, la cooperación descentralizada (COD), entendida como el conjunto de acciones de cooperación internacional que realizan o promueven los gobiernos locales y regionales (APC-COLOMBIA, 2013, p. 2), ha sido una modalidad promovida desde los asuntos internacionales de los GNC y desde el contexto en el cual que se despliega una parte de las políticas de cooperación para el desarrollo a nivel mundial.

Este contexto ha llevado a que los GNC comiencen a vincular dentro de sus actividades de gestión pública la cooperación internacional como un mecanismo para promover su internacionalización y/o gestionar recursos económicos y técnicos para sus proyectos y programas de desarrollo. Para ello, impulsan la creación de estructuras y procedimientos organizativos como un medio para institucionalizar, legitimar y establecer relaciones con sus socios internacionales. Alrededor de estas estructuras, materializadas en oficinas de cooperación o relaciones internacionales, secretarías, asesores en asuntos internacionales, agencias independientes, entre otros, se crean reglas, normas y directrices que guían el comportamiento del gobierno y moldean las expectativas generadas en el ámbito de acción correspondiente (JACKSON; SORENSEN, 2010).

En América Latina, esta tendencia ha sido más evidente en ciudades capitales e intermedias. Por esa razón, Bogotá y Ciudad de México se convierten en ejemplos representativos que reflejan gran parte de estas dinámicas en la región y permiten definir algunas variables de análisis. Así, por ejemplo, y pese a que estas dos ciudades pertenecen a modelos de estado diferentes (unitario y federal, respectivamente), el panorama administrativo e institucional en materia internacional muestra algunas
2. Este artículo adoptará la denominación de gobiernos no centrales, para referirse a las entidades territoriales que dentro de la división política se encuentran en el nivel intermedio y local y que cuentan con autonomía para administrar sus propios recursos naturales, financieros y sociales. 
características comunes y diferenciadas, vinculadas a los marcos jurídicos e institucionales que soportan los campos organizacionales para tal fin, los documentos programáticos y de política y las tendencias de sus iniciativas de cooperación de los últimos años.

Adicionalmente, su perfil como capitales las ha llevado a concebir la COD como una herramienta para promover sus asuntos internacionales que sobrepasa el modelo tradicional y asistencialista que por años ha caracterizado la cooperación Norte-Sur, lo cual puede ser resultado de los avances de sus procesos de institucionalización.

Atendiendo a este contexto, el artículo tiene como objetivo examinar los factores explicativos de los procesos de institucionalización de la cooperación descentralizada tomando como casos de estudio las ciudades capitales de Bogotá y Ciudad de México.

Para lograr tal propósito, una primera parte contextualiza los enfoques a través de los cuales puede ser explicada esta modalidad de cooperación. Posteriormente, se plantean algunos elementos fundamentales para comprender las dinámicas de la COD y el impulso de las estructuras institucionales para promover los asuntos internacionales. Para ello, se examina la institucionalización de la cooperación internacional de los casos de Bogotá y Ciudad de México para identificar las similitudes, diferencias, tendencias y oportunidades más representativas. Por último, una tercera parte, presenta unas consideraciones finales para complementar la reflexión.

Durante el proceso de investigación se tuvieron en cuenta fuentes primarias y secundarias las cuales fueron complementadas con el trabajo de campo realizado en Bogotá y Ciudad de México en los años 2016 y 2017, en el cual se adelantaron una serie de entrevistas semiestructuradas a funcionarios de las administraciones públicas de las dos ciudades capitales.

Los Gobiernos no Centrales (GNC) y el impulso de la cooperación descentralizada: un panorama general

La COD ha sido considerada como una modalidad de relacionamiento exterior de los GNC a través de la cual las entidades territoriales han impulsado sus asuntos internacionales.

A partir de esta constatación, el abordaje teórico para explicar las relaciones internacionales de los GNC y la COD ha estado soportado en la teoría de la interdependencia compleja de la década de los setenta, como punto de referencia para explicar la presencia de nuevos actores en el escenario internacional (KEOHANE; NYE, 1973; KEOHANE, 1984; KEOHANE; NYE, 1989).

En ese entonces, los asuntos globales empezaron a abordarse trascendiendo el enfoque Estado-céntrico de los realistas, en un entorno en el cual los "contactos, coaliciones e interacciones a través de fronteras estatales no son controladas por los órganos centrales de la política exterior de los gobiernos" (KEOHANE; NYE, 1973 apud KUZNETSOV, 2015, p. 35).

Este nuevo paradigma tuvo como grandes impulsores a Robert Keohane y Joseph Nye, quienes reconocen como actores del sistema internacional a la generalidad de agentes que confluyen en el escenario internacional tales como, agentes económicos y financieros, organizaciones 
no gubernamentales, organismos internacionales, GNC, además de los Estados y los operadores de la sociedad civil (DÍAZ, 2008). Los precursores de esta corriente buscan explicar los acontecimientos mundiales a partir de las relaciones entre estos actores, desde la lógica de la globalización y el libre mercado (DÍAZ, 2008, p. 36). Este enfoque reconoce la presencia de los GNC en el escenario internacional y permite, a partir de estos vínculos transnacionales, promover las iniciativas de cooperación internacional como un medio efectivo para el beneficio mutuo.

Al respecto, Cornago (2010) afirma que la presencia de los GNC en el ámbito internacional tiene su origen en la respuesta a los desafíos del contexto internacional. Una explicación de esto podría evidenciarse en el impulso de una nueva agenda internacional más integrada en los años setenta. En ese entonces, los temas politico-militares que centraron la atención de los realistas, fueron remplazados no solo por aspectos comerciales y financieros propios de la globalización, sino además por temas del desarrollo, que, en último término, deben tener una base territorial precisa. Es decir, bajo la corriente de la interdependencia se conciben una multiplicidad de temas en la agenda de las relaciones interestatales sin una jerarquía definida y en los cuales intervienen diversas instancias gubernamentales y en distintos niveles. Además de ello, se otorga una primacía a la cooperación por encima del conflicto (DÍAZ, 2008, p. 36).

En correspondencia con esta dinámica, en los años ochenta comienzan los estudios sobre la vinculación de los GNC en las relaciones internacionales y con ello un marco conceptual para definir estas iniciativas. Autores como Duchacek (1984, 1986, 2001), y luego Soldatos (1990), Kincaid (1990), Hocking (1993), Jeffery (1999) y Aguirre (2001, 2013) han establecido un marco de referencia en el que se plantean las discusiones alrededor del concepto más adecuado para definir las actividades internacionales de estos gobiernos (paradiplomacia, diplomacia multinivel, protodiplomacia, entre otros). De la misma manera, esta literatura explica, a partir del estudio de los regímenes federales, los factores que han promovido su vinculación en el escenario internacional, tales como la globalización, la interdependencia y los procesos de democratización y de descentralización administrativa. Otros autores han recogido estas discusiones para plantear escenarios a partir del análisis de casos en Norteamérica (KUZNETSOV, 2015; KINCAID, 1999; PAQUIN, 2003), en México (SCHIAVON, 2006, 2010) y en Brasil (SALOMÓN, 2007, 2008, 2012).

Estas posturas teóricas sobre paradiplomacia y sus debates conceptuales, permiten reconocer que los GNC son, en efecto, unidades cada vez más autónomas en su accionar, las cuales empiezan a ser protagonistas en el escenario internacional a partir de las interconexiones globales y la reducción progresiva de las fronteras, lo cual marca el inicio de un proceso de coexistencia entre los actores por excelencia de las relaciones internacionales -los estados- y los gobiernos subnacionales, en la búsqueda del desarrollo.

De esta manera, existen mecanismos que "facilitan" la inserción e interacción de dichos actores y, por tanto, la COD se constituye en una herramienta para demostrar el posicionamiento de los GNC en el escenario internacional y satisfacer sus intereses frente al desarrollo. 
Siguiendo con los postulados teóricos anteriormente descritos, y bajo una perspectiva institucionalista, las relaciones de interdependencia entre diversos actores del desarrollo que están presentes en el sistema internacional, se llevan a cabo mediante redes de reglas, normas y procedimientos que regulan los comportamientos y controlan sus efectos. Se trata de un conjunto de acuerdos gubernamentales que tienen un efecto sobre esas relaciones de interdependencia y que conforman lo que se denominan los regímenes internacionales (KEOHANE; NYE, 1989). Krasner (1982), los define como un "conjunto de principios, normas, reglas y procedimientos de toma de decisiones implícitos o explícitos en torno a los cuales convergen las expectativas de los actores en determinada área de las relaciones internacionales". En esta misma dirección, y como lo mencionan Dimaggio y Powell (1999), "los regímenes son instituciones ya que se basan en, dan homogeneidad a y reproducen las expectativas normales, y al hacerlo estabilizan el orden internacional".

Así, por ejemplo, desde la Segunda Guerra Mundial se han desarrollado un conjunto de reglas y procedimientos para guiar a los estados y actores transnacionales en una amplia variedad de áreas, entre las cuales se encuentran la ayuda internacional, la protección ambiental, la política monetaria internacional, el comercio internacional, etc (KEOHANE; NYE, 2011).

En este caso, el régimen internacional de ayuda al desarrollo ha estado fundamentado en argumentos políticos-estratégicos y económicos de los países desarrollados. Ha sido un sistema promovido por el Comité de Ayuda al Desarrollo (CAD) de la Organización para la Cooperación y el Desarrollo Económico (OCDE) a través del cual, los países llamados "donantes" han establecido reglas, políticas y prioridades de la ayuda al desarrollo a nivel mundial.

Este régimen se ha caracterizado por ser Estado-céntrico, es decir, ha estado soportado en el protagonismo del Estado el cual se ha visto en parte debilitado por las dinámicas de la globalización y con ello, la proliferación de nuevos actores (SANAHUJA, 2001).

Las dinámicas de este régimen han venido transformándose como consecuencia de la evolución en el concepto de desarrollo, los cambios en la geopolítica mundial y la participación de nuevos actores en el escenario internacional como las organizaciones de la sociedad civil, las empresas multinacionales, los GNC, y con ello, la promoción de nuevas modalidades, como la cooperación sur-sur y triangular y la cooperación descentralizada.

En este contexto, la presencia de los actores locales resulta fundamental no solo para promover procesos de desarrollo humano local sino además para impulsar la agenda internacional de desarrollo y avanzar en el propósito del desarrollo sostenible. En efecto, el marco institucional de la cooperación internacional reconoce la importancia del nivel local en los procesos de desarrollo y en la agenda de eficacia de la ayuda. Al respecto, Martínez y Sanahuja (2012) plantean que este reconocimiento es necesario para la gobernanza global a través de la participación de esos actores en la definición, planificación y gestión de las políticas de cooperación internacional. Así, los autores argumentan que los GNC pueden contribuir 
con la articulación multinivel como elemento para la gobernanza global y la aportación de valor específico a los procesos de desarrollo.

La COD implica entonces, una cooperación promovida desde los GNC de diferentes estados e involucra temas muy diversos de desarrollo presentados a escala regional y/o local. Es una cooperación que tiende a convertirse en un instrumento que aporte al fortalecimiento institucional de las autoridades locales, a las capacidades y oportunidades para el desarrollo local, a través de las asociaciones, la participación en redes, la transferencia de conocimiento y experiencias locales, la financiación de proyectos acordes con la realidad local, entre otros.

La COD y la institucionalización en los GNC

\section{Marco general}

La dinámica histórica de la cooperación internacional permite evidenciar como el discurso relacionado con la práctica de la COD ha estado fundamentado en el tradicional paternalismo Norte-Sur de la Ayuda Oficial al Desarrollo (AOD). Esto parece lógico en razón a que, un gran porcentaje de este tipo de relaciones se ha adelantado de manera especial entre la Unión Europea y América Latina.

En consecuencia, la práctica tradicional de la COD ha estado ligada al marco institucional del régimen internacional de ayuda que ha marcado una clara relación "donante-receptor" en la que predomina la asimetría y la financiación de proyectos de corto plazo mediante las subvenciones a ONG (Martínez y Sanahuja, 2009). Así, los GNC de países del norte se convirtieron en financiadores de iniciativas que, en algunos casos, eran implementadas por ONG de desarrollo. Durante muchos años, este fue el caso, por ejemplo, de las comunidades autónomas y ayuntamientos españoles, quienes empezaron a establecer oficinas y planes de cooperación internacional para otorgar recursos (en un gran porcentaje a través de convocatorias a ONG) con el propósito de financiar proyectos en países en desarrollo.

A partir de este contexto, se puede afirmar que a pesar de las bondades de la COD (mayor cercanía a la población, relaciones entre socios homólogos, fortalecimiento del desarrollo local, entre otros), esta modalidad terminó por trasladar las prácticas promovidas por la AOD desde los cooperantes miembros del CAD y se convirtió en un instrumento que acentuaba las relaciones Norte-Sur, la asimetría y las iniciativas de financiación económica desde GNC del norte hacia GNC de países del sur.

No obstante, ello, la COD comienza a tener nuevas dinámicas que favorecen las relaciones entre socios, con intereses locales de desarrollo, en los cuales los GNC asumen un mayor liderazgo y buscan un tipo de relación directa que contribuya con la gestión pública local. Este tipo de relaciones se soporta en las experiencias locales para la transferencia de conocimientos y buenas prácticas, el fortalecimiento institucional y el apoyo a la gobernabilidad local. Adicionalmente, se promueve la vinculación en los procesos locales no solo de las ONG sino, además, de las Universidades, los movimientos sociales, las empresas, entre otros. 
A partir de tales transformaciones, es posible evidenciar que a pesar de haber sido una modalidad de la AOD promovida desde el CAD, ha empezado a perfilarse de manera más acentuada como un instrumento de proyección internacional de los GNC y, por tanto, no solo responde a las necesidades de financiación de las entidades territoriales sino, además, a un componente de la gestión pública subnacional.

Por esa misma razón, la tendencia muestra cómo cada vez más, estas entidades comienzan a vincular dentro de sus actividades de gestión pública la cooperación internacional como un mecanismo para promover sus asuntos internacionales y/o gestionar recursos económicos y técnicos para sus proyectos y programas de desarrollo local. Para ello, impulsan la creación de estructuras y procedimientos organizativos como un medio para institucionalizar y legitimar estos procesos.

Así entonces, la vinculación de la cooperación internacional en los asuntos públicos no solo del nivel central sino del subnacional, supone avanzar hacia procesos de institucionalización para ordenar, coordinar, estructurar, sistematizar, conducir y planear las actividades internacionales que beneficien la coherencia, la complementariedad, la armonización y la apropiación de los programas o proyectos que se implementan (GRANDAS; PRADO, 2017).

Esto parece lógico en razón a que, "la estructura, el diseño y la funcionalidad de las agencias de cooperación internacional, organismos multilaterales, mecanismos de cooperación, etc, juegan un rol trascendental y permiten determinar la capacidad de estos entes para conseguir sus objetivos" (KARNS; MINGTS, 2010, en PRADO; OCHOA, 2017, p. 290).

Desde la perspectiva del institucionalismo y el análisis organizacional, se plantea como los campos organizacionales, que para este caso son las oficinas de relaciones internacionales o cooperación internacional, existe una homogeneidad de prácticas y acuerdos y una reproducción de estructuras y reglas, generando un isomorfismo institucional en el que se establecen normas y procedimientos que son los que terminan por legitimar los procesos (DIMAGGIO; POWELL, 1999).

Al respecto Fejerskov (2016) plantea como el campo de la cooperación para el desarrollo ha estado expuesto a los cambios de los regímenes internacionales lo cual ha determinado las prácticas y discursos de moda. De esta manera, y de acuerdo con la teoría institucional, a medida que las ideas influyen en las acciones, pueden convertirse en "lógicas institucionales" que terminan por dirigir los cambios institucionales y organizacionales.

En esta misma dirección, los nuevos actores que participan en la cooperación, como los GNC, las ONG, las empresas, los movimientos sociales, etc., llevan consigo una cultura organizacional particular y contextos que configuran su modo de operar y su relación con otros actores. Así, algunos de ellos desafían la legitimidad y la autoridad tradicional y organizacional que ha dominado por décadas las relaciones norte-sur y otros, participan o muestran interés en los acuerdos, normas y principios globales que gobiernan y homogeneizan las prácticas y los patrones de la cooperación internacional (FEJERSKOV, 2016). 
El contexto descrito muestra cómo los GNC terminan por acogerse a ciertas reglas y a asumir ciertos patrones con el propósito de mantener relaciones con sus socios cooperantes y replicar prácticas organizacionales como mecanismos de legitimación de su acción internacional.

En este marco, Salomón (2012) plantea, por ejemplo, que la COD puede ser considerada como una institución internacional refiriéndose con este término a un conjunto de ideas, arreglos institucionales, normas, reglas y prácticas formalizadas. De esta manera, la COD es una política pública con arreglos institucionales resultado de prácticas específicas de actores individuales.

Bajo este mismo contexto y de acuerdo con Meyer y Rowan (1999), comúnmente se crean profesiones, políticas y programas que vienen acompañados de productos y servicios para ser producidos y ofrecidos. Esta dinámica genera nuevas organizaciones y obliga a las que ya funcionan a vincular nuevas prácticas, procedimientos y reglas institucionalizadas en la sociedad. De este modo, las organizaciones que siguen este camino automáticamente incrementan su legitimidad y su supervivencia más allá de la eficacia y pertinencia de las prácticas, reglas y procedimientos adquiridos. Así, muchas organizaciones reflejan marcadamente los mitos y ceremonias (como rutinas institucionales), más que las demandas de sus actividades de trabajo.

Desde la perspectiva de los procesos relacionados con la cooperación internacional en los GNC, este planteamiento permite examinar cómo la vinculación de los temas internacionales en sus estructuras organizacionales termina por crear nuevos espacios, reglas, procedimientos y prácticas de gestión pública del orden subnacional. Estos a menudo obedecen y surgen como una reproducción de modelos prestablecidos, que en algunas ocasiones vienen influenciados por los dictámenes del régimen de ayuda internacional.

Al respecto, Krasner (2001) argumenta que las instituciones ofrecen guiones que hacen que los individuos interioricen concepciones que provienen de las estructuras institucionales, lo que termina generando patrones que se transmiten y reproducen por mimetismo. Sin embargo, estos patrones no siempre pueden ser adecuados para el contexto en el cual se aplican.

En el ámbito de la COD y los procesos de institucionalización, esto parece bastante claro. Un municipio pequeño puede tener el interés de impulsar un área organizacional para promover sus asuntos internacionales, pero su capacidad técnica, profesional y financiera no le permitirá llevar a cabo una gestión eficiente y eficaz como la de una ciudad capital.

De la misma manera, una organización puede decidir nuevas normas y reglas que emanan del medio institucional y que legitiman sus procesos, pero en su interior mantener las prácticas habituales e informales. Al respecto, algunos GNC, bajo el ideal de legitimar sus asuntos internacionales orientan su accionar hacia la construcción de estrategias de internacionalización y/o cooperación internacional, que no siempre se traducen en una mayor eficacia y eficiencia de sus actividades y tan solo se convierten en el medio para evidenciar ante otros operadores con los que existe una articulación subordinada, el grado de institucionalización y de planeación de 
sus asuntos internacionales a fin de presentarse, "como una organización adecuada, racional y moderna” (MEYER; ROWAN, 1999, p. 83).

\section{El panorama latinoamericano}

A la luz de los anteriores planteamientos, la tendencia en algunas ciudades de países en América Latina como México, Colombia, Chile, Perú, Argentina y Brasil, entre otros, muestra como la cooperación internacional y los asuntos internacionales han venido vinculándose en las estructuras organizacionales de gestión pública con algunas características que se reflejan en la conformación de oficinas, legislaciones, políticas, estrategias, recursos financieros y humanos.

Zubelzú (2008), por ejemplo, define cuatro tipos de diseño organizacional o institucional y de perfiles de gestión de las provincias argentinas: a) provincias en las que las áreas, subsecretarías o direcciones encargadas de los asuntos externos se vinculan dentro de la estructura de un Ministerio de Producción (Buenos Aires, Chaco, Santa Fe y la Pampa); b) provincias que tienen o han tenido un área para trabajar específicamente los temas internacionales desde un enfoque que sobrepasa el ámbito productivo-comercial, como las Secretarias y Direcciones de Comercio Exterior, Relaciones Internacionales y/o Cooperación (Chaco, Salta y Tierra del Fuego, entre otras); c) provincias que tienen agencias específicas con algún nivel de autonomía y a través de las cuales se busca promover eventos de exportaciones (Agencia Pro Córdoba, Pro Mendoza, Pro Río Negro y BAexporta); y d) provincias que, a pesar de establecer algunas actividades internacionales, no cuentan con áreas para manejar estos asuntos (San Luis, Santa Cruz, Formosa, Río Negro y Tucumán).

Schiavon (2010), por su parte, establece niveles de internacionalización de las entidades federativas en México (bajo, medio, alto y muy alto) a través del análisis de la estructura gubernamental, la actividad política y la actividad económica. Frente a la primera variable de análisis, este autor plantea que la estructura gubernamental está definida por la existencia de un órgano de vinculación con el exterior a través de una dirección o secretaría dentro de la secretaría de economía estatal y, mediante un órgano de vinculación que depende del ejecutivo estatal, como las oficinas de asuntos internacionales de menor nivel que una secretaría adscritas a la oficina del gobernador. De esta investigación se desprende que los estados con mayores niveles de relacionamiento exterior fueron los que contaban con un espacio u oficina de relaciones internacionales para promover una activa participación económica y política internacional.

Milani y Ribeiro (2010) plantean que en general, algunos municipios de Brasil han establecido espacios para sus asuntos internacionales mediante figuras como un secretariado municipal (Camaçari, Foz Do Igaçu, Porto Alegre, Santa Maria, entre otros), un servicio dependiente del secretariado (Belo Horizonte, Joinville, Jundiaí, Santo André, Sorocaba) o un asesor/coordinador (Fortaleza, Belém, Boa Vista, Rio Branco, Caxias Do Sul, entre otros). Adicionalmente, los autores ponen de presente que estos municipios con estructuras formales realizan tres tipos 
de actividades paradiplomáticas: participación en redes trasnacionales, participación en congresos y acontecimientos internacionales, acuerdos de hermanamiento entre ciudades, mercadotecnia de ciudades, pertenencia a asociaciones internacionales, y establecimiento de redes regionales y globales.

Para el caso de Colombia, Zamora (2016), propone una valoración del nivel de participación internacional de tres ciudades capitales, Bogotá, Cali y Medellín entre 2001 y 2012, sobre la base de los trabajos de Schiavon de 2006 y 2010 y sus niveles de clasificación muy alto, alto, medio y bajo, en las variables de estructura gubernamental, actividad económica y actividad política. Para aplicar esta tipología en Colombia, Zamora decide vincular a la estructura gubernamental un componente adicional: la existencia de un plan de políticas o estrategias con continuidad durante el periodo de análisis, en especial, dentro del plan de desarrollo municipal. Los resultados de su análisis muestran, en términos generales, que Bogotá y Medellín cuentan con un nivel alto de participación internacional (con marcadas diferencias en las estructuras gubernamentales) y Cali tiene un grado de participación bajo con una valoración nula en el componente gubernamental.

De la misma manera, Grandas y Prado (2017), establecen el grado de institucionalización de la cooperación descentralizada en la gobernación de Cundinamarca, Colombia, tomando como base las variables relacionadas con la legislación ad hoc, los sistemas de información, la rendición de cuentas, el personal capacitado, el presupuesto asignado y los mecanismos de coordinación. A partir de ello, concluyen que, a pesar de los avances conseguidos en años recientes, esta entidad del orden departamental requiere establecer e implementar rutas estratégicas que den cuenta de una mayor planeación y articulación de sus procesos de cooperación internacional.

En general, se podría decir que en América Latina existen algunos factores explicativos comunes y similares que definen la práctica y la tendencia de la institucionalización de la cooperación internacional y los asuntos internacionales de los GNC. Dentro de ellos, se pueden destacar: el marco legal e institucional a nivel nacional que legitima el ejercicio de la internacionalización y la cooperación de un GNC, el marco jurídico y legal que soporta las estructuras organizacionales dedicadas a tal fin, la vinculación de los asuntos internacionales y de cooperación en los planes y programas de desarrollo lo cual expresa, entre otras cosas, la voluntad política del mandatario de turno, los documentos de política representados en estrategias de cooperación internacional y/o internacionalización y en las prácticas y actividades propias del GNC, el perfil profesional del personal vinculado, el grado de articulación de los procesos a nivel local, regional y nacional, las partidas presupuestarias, los procesos de rendición de cuentas y los sistemas de información.

A partir de estos factores, se pueden identificar algunas similitudes y patrones que explican los avances y retrocesos de esta institucionalización y que a su vez sirven para examinar su grado de influencia sobre la práctica de los asuntos internacionales y de cooperación desde un GNC. 
Los casos de Bogotá y Ciudad de México

\section{Marco jurídico e institucional}

Un primer elemento por destacar, tiene que ver con los marcos normativos e institucionales para legitimar el ejercicio de la cooperación internacional en los casos objeto de estudio.

Colombia es una república unitaria y descentralizada. Se consideran entidades territoriales los departamentos, distritos, municipios y territorios indígenas, las cuales "gozan de autonomía para la gestión de sus intereses". Los municipios son considerados como las "entidades fundamentales de la división política administrativa del Estado", sobre las cuales recae la responsabilidad, entre otras cosas, de "ordenar el desarrollo de su territorio" ... De esta manera, la división político-administrativa del país está organizada en 32 Departamentos, 1.096 municipios y 5 Distritos.

Por su parte, la constitución política de los Estados Unidos Mexicanos establece que México, como comúnmente se conoce, es "una República representativa, democrática, federal, compuesta de Estados libres y soberanos en todo lo concerniente a su régimen interior; pero unidos en una federación establecida según los principios de esta ley fundamental” (Art. 40). La división político-administrativa está conformada por sus 32 entidades federativas o Estados y sus 2446 municipios.

Si bien, tanto en Colombia como en México el gobierno nacional sigue manteniendo el monopolio de las relaciones internacionales y de política exterior del estado, el ordenamiento jurídico de los dos países reconoce ciertas competencias a los GNC para la acción internacional. No obstante, el tipo de estado (unitario o federal) puede marcar algunas diferencias en sus actividades paradiplomáticas.

En el caso de Colombia, en su calidad de república unitaria, el principio de autonomía territorial junto a los derechos fundamentales y los procesos de descentralización, se convierten en los principales legitimadores de las actuaciones internacionales de las entidades territoriales del país. La Constitución Política de 1991 impulsó decididamente la consolidación de la autonomía la cual vino acompañada del proceso de descentralización fiscal, política y de servicios. A través del artículo 356, por ejemplo, creó el Sistema General de Participaciones (SGP) de los departamentos, distritos y municipios, con el propósito de proveer los recursos para financiar adecuadamente la prestación de los servicios a su cargo.

La autonomía territorial se manifiesta no solo como principio fundamental de la organización del estado, sino además como atributo o cualidad de las entidades territoriales. Esta última característica tiene especial relevancia en razón a que le otorga a los GNC un estatus que le permite gestionar los intereses de la comunidad que representa. Por esa misma razón, y para dar vida a tal principio, la Constitución estableció derechos en favor de las entidades territoriales, para garantizar el respeto al principio de la autonomía (ROBLEDO, 2010).

No obstante, ello, como un estado unitario, y a diferencia de un estado federal como lo es México, existe una concentración indivisible 
del poder, por lo que las políticas públicas y los propósitos en relaciones internacionales están fuertemente ligados y sujetos a los desarrollos del nivel central.

En el caso de México, y más allá de la autonomía que confiere la constitución, existe un marco normativo que claramente dota de mayores atribuciones y faculta a sus entidades federativas para establecer actividades paradiplomáticas. A diferencia de Colombia, el hecho de que cada estado pueda establecer su propia constitución, dentro de los límites que establece la Constitución Federal, otorga una fuerte base legal para planificar e implementar los asuntos internacionales de manera más autónoma, sostenible y adaptada a las prioridades del territorio.

De la misma manera, la Ley sobre Celebración de Tratados de 1992 del Gobierno Federal abrió la posibilidad de que los Estados y municipios tuvieran la potestad de adelantar acuerdos de cooperación. Esta ley vinculó (más allá de los tratados), la figura de los acuerdos interinstitucionales, definidos en el Artículo 2, parte II, como

\footnotetext{
el convenio regido por el derecho internacional público, celebrado por escrito entre cualquier dependencia u organismo descentralizado de la Administración Pública Federal, Estatal o Municipal y uno o varios órganos gubernamentales extranjeros u organizaciones internacionales, cualquiera que sea su denominación, sea que derive o no de un tratado previamente aprobado (CONGRESO DE LOS ESTADOS UNIDOS MEXICANOS, 1992).
}

Ligado a estas atribuciones institucionales en los dos países, los vínculos internacionales de los GNC han sido promovidos como consecuencia de los procesos de globalización, democratización y descentralización. En el caso de México, por ejemplo, la internacionalización de estos gobiernos estuvo muy ligada a la globalización y en especial, a la liberalización del comercio mundial y la firma de acuerdos comerciales como el Tratado de Libre Comercio de Norteamérica de 1994 (TLCN) y el Tratado de Libre Comercio México-Unión Europea del año 2000. Estos tratados llevaron a relaciones de cooperación entre los GNC de los países involucrados (DÍAZ, 2007).

Aunque los GNC de los dos países, dentro de los límites que les otorga la constitución nacional, gozan de autonomía y no se les impide institucionalizar y gestionar sus asuntos internacionales, la experiencia demuestra que solo aquellos que cuentan con mayor capacidad presupuestal y de gestión, han apostado por estructuras de proyección internacional.

Además de eso, es posible observar que el nivel intermedio de la división político-administrativa de los dos países (departamentos en Colombia y estados en México), tiene mayores posibilidades que los municipios para establecer estructuras institucionales gracias a su capacidad técnica, organizacional y financiera. Así, y de acuerdo con Schiavon y López Farfán (2005 apud DÍAZ, 2007), en todos los estados mexicanos existe alguna dependencia en calidad de subsecretaría, dirección o coordinación, que ejerce las funciones relacionadas con los asuntos internacionales.

El caso de los municipios parece similar. En ambos países estas entidades territoriales se caracterizan por su diversidad socioeconómica e institucional, por lo cual, en un gran porcentaje existe un desconoci- 
miento extendido por parte de muchas de las administraciones locales de menor desarrollo respecto a los diversos mecanismos para su proyección internacional y una generalizada ausencia de marcos estratégicos que permitan planificar una agenda exterior que beneficie los procesos de desarrollo local y que responda a las prioridades plasmadas en los planes de desarrollo municipal.

Los primeros pasos relacionados con la estructura organizacional en Bogotá y Ciudad de México (CDMX) se remontan a las décadas de los ochenta y noventa, respectivamente, en los cuales se comienza a vincular a los asuntos públicos las relaciones internacionales en especial, a través de la cooperación internacional. Esto parece natural, debido a que la COD como una modalidad del régimen internacional de ayuda fue la manera a través de la cual muchos GNC en América Latina emprendieron sus vínculos paradiplomáticos.

La experiencia de Bogotá en temas de cooperación descentralizada data de 1982 cuando la ciudad firmó un protocolo de hermanamiento de ciudades capitales iberoamericanas a través del cual se inició un proceso de inserción internacional para que la ciudad estableciera con otras ciudades relaciones de cooperación e intercambio mutuo. (SDP, 2007).

Adicional a esta primera iniciativa, la Constitución Política de Colombia de 1991 dio un impulso importante a los gobiernos municipales y los procesos de descentralización que a su vez generó en Bogotá la necesidad de prepararse para su inserción internacional.

Atendiendo a esta situación, a finales de los noventa comienzan a definirse áreas organizacionales dentro de la administración distrital para coordinar y dirigir los temas internacionales. A partir de entonces se evidenciaron varios cambios respaldados por marcos jurídicos y legales que intentaban consolidar una estructura institucional que liderara y articulara la agenda internacional del distrital hasta llegar a lo que hoy es la Dirección Distrital de Relaciones Internacionales, instancia encargada de articular, coordinar y planear los asuntos internacionales de la ciudad.

El cuadro No. 1 muestra los antecedentes institucionales más relevantes en materia de cooperación y/o asuntos internacionales de Bogotá:

Cuadro No. 1 Evolución histórica de los espacios institucionales para la cooperación y los asuntos internacionales de Bogotá

\begin{tabular}{l|l|l}
\hline Alcalde & $\begin{array}{l}\text { Estructuras institucionales creadas para la } \\
\text { cooperación y los asuntos internacionales }\end{array}$ & Actividad, objetivo y/o función principal \\
\hline $\begin{array}{l}\text { Enrique Peñalo- } \\
\text { sa (1998-2000) }\end{array}$ & $\begin{array}{l}\text { Asesoría para la nación y las relaciones } \\
\text { internacionales adscrita a la Secretaría priva- } \\
\text { da del Alcalde }\end{array}$ & $\begin{array}{l}\text { Promover la agenda internacional, la promoción de } \\
\text { ciudad y la cooperación internacional }\end{array}$ \\
\hline $\begin{array}{l}\text { Antanas } \\
\text { Mockus }\end{array}$ & $\begin{array}{l}\text { Consejería región y competitividad adscrita } \\
\text { a la Alcaldía hasta 2002 cuando fue asumi- } \\
\text { da por el Departamento Administrativo de } \\
\text { Planeación Distrital. }\end{array}$ & $\begin{array}{l}\text { Atender temas como las relaciones exteriores y la } \\
\text { diplomacia de la ciudad, la cooperación y el comercio } \\
\text { exterior y la integración entre Bogotá y Cundinamarca y } \\
\text { los demás departamentos de la región central }\end{array}$ \\
\hline
\end{tabular}




\begin{tabular}{l|l|l}
\hline Alcalde & $\begin{array}{l}\text { Estructuras institucionales creadas para la } \\
\text { cooperación y los asuntos internacionales }\end{array}$ & Actividad, objetivo y/o función principal \\
\hline $\begin{array}{l}\text { Red Distrital de Cooperación para el desar- } \\
\text { rollo liderada por la Alcaldía Mayor (2005) } \\
\text { Dirección de cooperación regional, nacional } \\
\text { e internacional adscrita a la Secretaría Distri- } \\
\text { tal de Planeación (2006) } \\
\text { Oficina de Banca Multilateral y Cooperación } \\
\text { adscrita a la Secretaría de Hacienda (2006) }\end{array}$ & $\begin{array}{l}\text { Facilitar la articulación y las relaciones de las entidades dis- } \\
\text { tritales y otros actores internacionales para establecer linea- } \\
\text { mientos y priorizar proyectos e iniciativas de cooperación. } \\
\text { Dar cumplimiento a todas las estrategias orientadas a la } \\
\text { cooperación regional, nacional e internacional de Bogotá. } \\
\text { Coordinar la gestión de los proyectos con recursos de la } \\
\text { banca multilateral. Esta oficina fue posteriormente fusio- } \\
\text { nada con la Dirección Distrital de Crédito Público }\end{array}$ \\
\hline $\begin{array}{l}\text { Samuel Moreno } \\
\text { Rojas } \\
(2008-2011)\end{array}$ & $\begin{array}{l}\text { Dirección Distrital de Relaciones Internacio- } \\
\text { nales adscrita a la Secretaría General }\end{array}$ & $\begin{array}{l}\text { Diseñar y promover políticas y estrategias tendientes } \\
\text { al fortalecimiento de las relaciones internacionales de } \\
\text { Bogotá D.C. con otras ciudades, países y organizaciones } \\
\text { del ámbito internacional. }\end{array}$ \\
\hline
\end{tabular}

Fuente: elaboración propia con base en SDP (2011), Decreto 550 de 2006, Decreto 163 de 2008 .

La creación de la Dirección Distrital de Relaciones Internacionales en el 2008 impulsó el surgimiento de una nueva institucionalidad representada por el Comité Interinstitucional de Cooperación Internacional (CICI), que opera de manera tripartita con la Dirección Distrital de Relaciones Internacionales (DDRI) ${ }^{3}$ perteneciente a la Secretaría General, la Secretaría Distrital de Hacienda ${ }^{4}$ y la Secretaría Distrital de Planeación 5 .

De la misma manera, la Alcaldía Mayor de Bogotá bajo el mandato de Gustavo Petro (2012-2015), respaldó la institucionalidad de la cooperación internacional a través de la validación y apoyo a las acciones desarrolladas por la Dirección Distrital de Relaciones Internacionales, entre las que se destaca, entre otras, la formulación de la Estrategia de Cooperación Internacional de Bogotá 2012-2016.

Como una última reforma, el Decreto 425 de 2016 modifica la estructura organizacional de la Secretaría General de la Alcaldía de Bogotá, por lo cual, la Dirección Distrital de Relaciones Internacionales pasa a ser parte de la Subsecretaría técnica de la Secretaría General, se elimina la subdirección de asuntos internacionales y se mantiene la la subdirección de proyección internacional.

El caso de Ciudad de México ha tenido algunas particularidades las cuales marcan diferencias con Bogotá. Como capital del país, hasta 1997 el jefe de gobierno de CDMX era elegido por el presidente de la república por lo cual, la dinámica administrativa estaba muy centralizada. Hasta ese entonces, desde el Departamento del Distrito Federal (DDF) de la Presidencia de la República no se contaba con un espacio institucional encargado de las relaciones internacionales de la ciudad en razón a que, estos asuntos estaban en cabeza de la Secretaría de Relaciones Exteriores del gobierno federal (CGAI, 2016).

Sin embargo, en 1996 el mandatario de turno, Oscar Espinosa Villarreal, avanza en la creación de una oficina encargada de las relaciones internacionales de la Ciudad, con el objetivo de atender al cuerpo diplomático y consular y responder a las demandas tradicionales de protocolo de una ciudad capital (CGAI, 2016).

A partir de la reforma de 1996 se crea el gobierno del Distrito Federal, fecha en la cual el jefe de gobierno empieza a ser elegido por voto

3. Creada mediante Decreto 163 de junio de 2008: encargada de posicionar los temas de integración e inserción regional, nacional e internacional de Bogotá a través de la construcción de lineamientos y el acompañamiento como ente articulador entre diferentes actores que trabajan en torno al desarrollo de la ciudad.

4. A través de la Oficina de Banca Multilateral y Cooperación, la cual coordina a las entidades distritales en la ejecución de los proyectos financiados con recursos de banca multilateral; gestiona y apoya a las entidades distritales en su gestión de recursos de cooperación internacional en procura de obtener mayores ingresos para la financiación del desarrollo de la ciudad.

5. A través de la Dirección de Integración Regional Nacional e Internacional. 
popular y la ciudad comienza a tener un proceso gradual de descentralización política y administrativa. Luego, con la reforma del año 2016, esta entidad territorial cambia de nombre, pasando de Distrito Federal al de Ciudad de México.

Se podría decir entonces, que es a partir de 1997, cuando se puede demostrar claramente los inicios del proceso de institucionalización de los asuntos internacionales y de cooperación internacional de CDMX, lo que su vez, permite evidenciar una serie de altibajos durante los últimos 15 años.

El cuadro No. 2 permite evidenciar los acontecimientos más importantes en la conformación de la institucionalidad de los asuntos internacionales y de cooperación de CDMX:

Cuadro No. 2

Evolución histórica de los espacios institucionales para la cooperación y los asuntos internacionales de Ciudad de México

\begin{tabular}{l|l|l}
\hline Alcalde & $\begin{array}{l}\text { Estructuras institucionales } \\
\text { de la cooperación y los } \\
\text { asuntos internacionales }\end{array}$ & Actividad, objetivo y/o función principal \\
\hline $\begin{array}{l}\text { Cuauhtémoc } \\
\text { Cárdenas Solórzano } \\
\text { (1997-1999) }\end{array}$ & $\begin{array}{l}\text { Dirección sobre Asuntos } \\
\text { Internacionales del Gobierno } \\
\text { del DF (GDF) adscrita a la } \\
\text { jefatura de gobierno }\end{array}$ & $\begin{array}{l}\text { Promover una estrategia de vinculación de la ciudad con } \\
\text { el mundo que incluye giras del jefe de gobierno, firma de } \\
\text { hermanamientos con ciudades de América Latina y Estados } \\
\text { Unidos }\end{array}$ \\
\hline $\begin{array}{l}\text { Andrés Manuel López } \\
\text { Obrador (2000-2005) }\end{array}$ & Subdirección de Protocolo & $\begin{array}{l}\text { Promover prioritariamente las relaciones protocolarias de la } \\
\text { ciudad }\end{array}$ \\
\hline $\begin{array}{l}\text { Marcelo Luis Ebrard } \\
\text { Casaubón (2006-2012) }\end{array}$ & $\begin{array}{l}\text { Coordinación General de } \\
\text { Relaciones Internacionales } \\
\text { (CGRI) }\end{array}$ & $\begin{array}{l}\text { Promover una fuerte visibilidad y proyección internacional de } \\
\text { la ciudad mediante la participación en redes internacionales de } \\
\text { gobiernos locales }\end{array}$ \\
\hline $\begin{array}{l}\text { Miguel Ángel } \\
\text { Mancera Espinosa } \\
\text { (2012-2018) }\end{array}$ & $\begin{array}{l}\text { Coordinación General de } \\
\text { Asuntos Internacionales } \\
\text { (CGAI) }\end{array}$ & $\begin{array}{l}\text { Consolidar a la Ciudad como una capital con presencia y } \\
\text { relevancia a nivel internacional mediante el fortalecimiento y } \\
\text { diversificación de sus vínculos de cooperación con gobiernos } \\
\text { locales, gobiernos nacionales, redes de ciudades, organismos } \\
\text { internacionales, el cuerpo diplomático acreditado en México y las } \\
\text { misiones de México en el extranjero }\end{array}$ \\
\hline
\end{tabular}

Fuente: elaboración propia con base en CGAI (2016).

Los antecedentes anteriormente descritos muestran diferencias relevantes de una administración a otra. Así por ejemplo, durante la administración de Andrés Manuel López Obrador los asuntos internacionales pasaron a un segundo plano y la institucionalidad se vio afectada dejando de lado la Dirección y creando una subdirección de Protocolo manejada por una sola persona. Por su parte, la administración de Marcelo Luis Ebrard Casaubón (2006-2012) quiso recatar la anterior Dirección creando nuevamente las direcciones de Protocolo y Proyectos Especiales y promoviendo la visibilidad y proyección internacional de la ciudad mediante una activa participación en redes internacionales de gobiernos locales, en el restablecimiento de algunos hermanamientos y en reconocimientos importantes como el nombramiento del jefe de gobierno como presidente del Consejo Mundial de Alcaldes por el Cambio Climático en 2009 y el galardón con el premio de Mejor Alcalde del Mundo por la Fundación City Mayors en 2010 (LARA, 2015). 
A pesar de que en los dos últimos gobiernos (2006-2012, 2012-2018) se evidencia el interés en la permanencia de una estructura dedicada a los asuntos internacionales de la ciudad, hasta el año 2015 se pueden observar altibajos organizacionales en el sentido en que el espacio para tal fin dependía de la oficina del jefe de gobierno y, por tanto, estaba ligado a la voluntad política del gobierno de turno. Esta situación no le permitía a la Coordinación General de Asuntos Internacionales de la Jefatura de Gobierno de la Ciudad de México (CGAI) contar con recursos financieros propios, ni planear a mediano y largo plazo. Adicionalmente, la CGAI no estaba facultada por la ley para ejercer su función de coordinación interinstitucional con las otras secretarías del gobierno de la ciudad, las cuales habían estado estableciendo importantes vínculos internacionales.

Sin embargo, estos procesos de institucionalización cobran mayor relevancia a partir de dos avances particulares. El primero de ellos, relacionado con la aprobación del Programa Especial de Acción Internacional de la ciudad en 2016. De acuerdo con el Programa

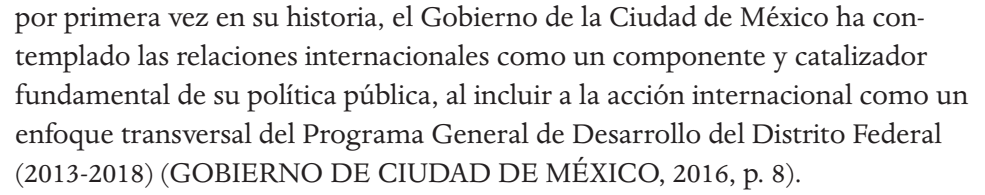

El segundo avance tiene que ver con la aprobación de la Constitución de la Ciudad de México, aprobada el 31 de enero de 2017. A través de su artículo 20, la ciudad ratifica su cualidad de "Ciudad global" y plantea en el numeral 2 que:

\begin{abstract}
La Ciudad de México promoverá su presencia en el mundo y su inserción en el sistema global y de redes de ciudades y gobiernos locales, establecerá acuerdos de cooperación técnica con organismos multilaterales, instituciones extranjeras y organizaciones internacionales, de conformidad con las leyes en la materia, y asumirá su corresponsabilidad en la solución de los problemas de la humanidad, bajo los principios que rigen la política exterior (GOBIERNO DE CIUDAD DE MÉXICO, 2017, p. 43).
\end{abstract}

De la misma manera, la Constitución establece que "los poderes públicos, organismos autónomos y alcaldías podrán celebrar acuerdos interinstitucionales con entidades gubernamentales equivalentes de otras naciones y con organizaciones multinacionales, que favorezcan la cooperación internacional y las relaciones de amistad, de conformidad con las leyes en la materia”.

Pero quizás lo más importante de esta constitución frente a la institucionalización de los asuntos internacionales de CDMX es que se plantea que el Gobierno de la Ciudad de México,

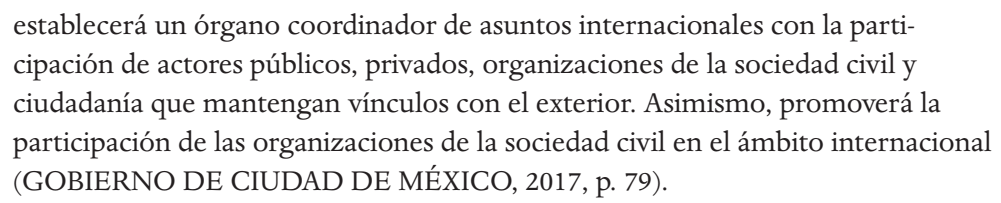

Lo consignado en la constitución reviste especial importancia en razón a que dota de un marco normativo en el cual se fortalece la institucionalidad y el respaldo de los asuntos internacionales y la cooperación y evita las limitaciones de su accionar institucional que durante varios 
años había dependido del mandatario de turno y, por tanto, había estado condicionado a la voluntad política del gobierno.

No obstante, ello, es fundamental que las acciones internacionales de CDMX fortalezcan su accionar a través de una mayor sostenibilidad de su institucionalidad que permita tener mayor claridad del marco legal en el que se inscriben esos procesos, establecer las facultades de la CGAI y de su personal junto a las partidas presupuestarias para llevar a cabo su agenda internacional.

Los antecedentes anteriormente descritos demuestran como los temas internacionales y de cooperación terminaron por penetrar y vincular un nuevo campo organizacional y de gestión pública en las estructuras institucionales de los gobiernos de Bogotá y CDMX.

La experiencia indica, además, que los avances en esta materia, responden a "lógicas institucionales" diversas que, en todo caso, mantienen una característica común relacionada con el interés y la voluntad política del mandatario de turno.

Una marcada diferencia de las dos ciudades se demuestra en el perfil organizacional para el manejo de sus relaciones internacionales desde el gobierno. Para el caso de México, se observa que, a pesar de los cambios de administración, estos temas se mantuvieron atados al despacho del alcalde, lo que puede verse como un aspecto positivo en razón a que le otorga un estatus y una jerarquía importante en el gobierno de la ciudad. Sin embargo, ante la ausencia de marcos normativos que blindaran este campo organizacional, esta situación terminó afectando la continuidad y sostenibilidad de los procesos en razón a que dependía del "Interés y voluntad política” del mandatario de turno. Por esa misma razón, sin duda la Constitución de la ciudad representa un avance significativo que impacta el área organizacional y permite planear a mediano y largo plazo las acciones internacionales.

Bogotá, por su parte, ha mostrado un mayor soporte jurídico e institucional para tal fin; sin embargo, durante varios años evidenció constantes cambios organizacionales lo que pudo impactar la sostenibilidad de los procesos y la coordinación y articulación de estos asuntos. Solo hasta 2006, cuando se establece por decreto la Dirección Distrital de Relaciones Internacionales, se empezó a tener mayor claridad en la definición de una estructura institucional para coordinar, articular y representar las prioridades en materia internacional.

Llama la atención que la estructura organizacional de Ciudad de México sobresale por su tamaño mientras que la de Bogotá tiende a reducirse. En este último caso, la percepción es que, con la última reforma de la Secretaría General, la DDRI perdió peso dentro del organigrama al quedar adscrita a la subsecretaría técnica de la Secretaria General y además, con la decisión de eliminar la subdirección de asuntos internacionales no se valoraron las responsabilidades y los desarrollos que durante las pasadas administraciones había tenido esta instancia. 
Cuadro No. 3 Estructura organizacional para la coordinación de los asuntos internacionales de la Alcaldía de Bogotá (2017)

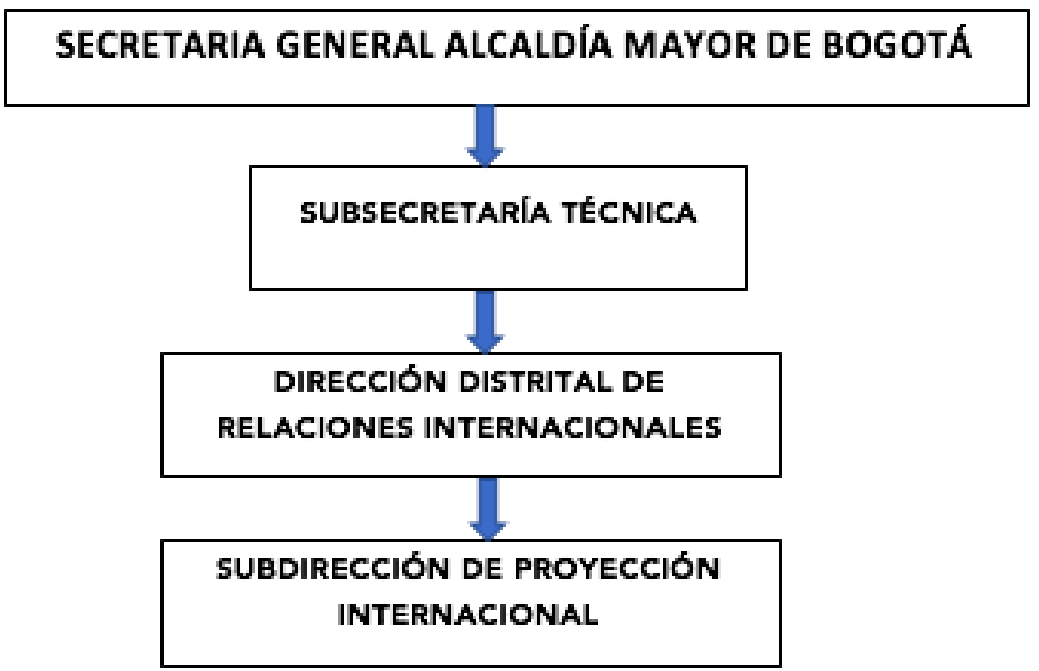

Fuente: elaboración propia con base en el Decreto 425 de 2016 del Distrito

Ciudad de México, por su parte, muestra como a pesar de la debilidad jurídica para proteger la estructura organizacional, ha contado dentro de su organigrama con una Dirección General de Cooperación Internacional a través de la cual funcionan la subdirección de cooperación bilateral y descentralizada y la jefatura de unidad departamental de relación con organismos y redes internacionales.

Cuadro No. 4

Estructura organizacional de los asuntos internacionales de CDMX (2017)

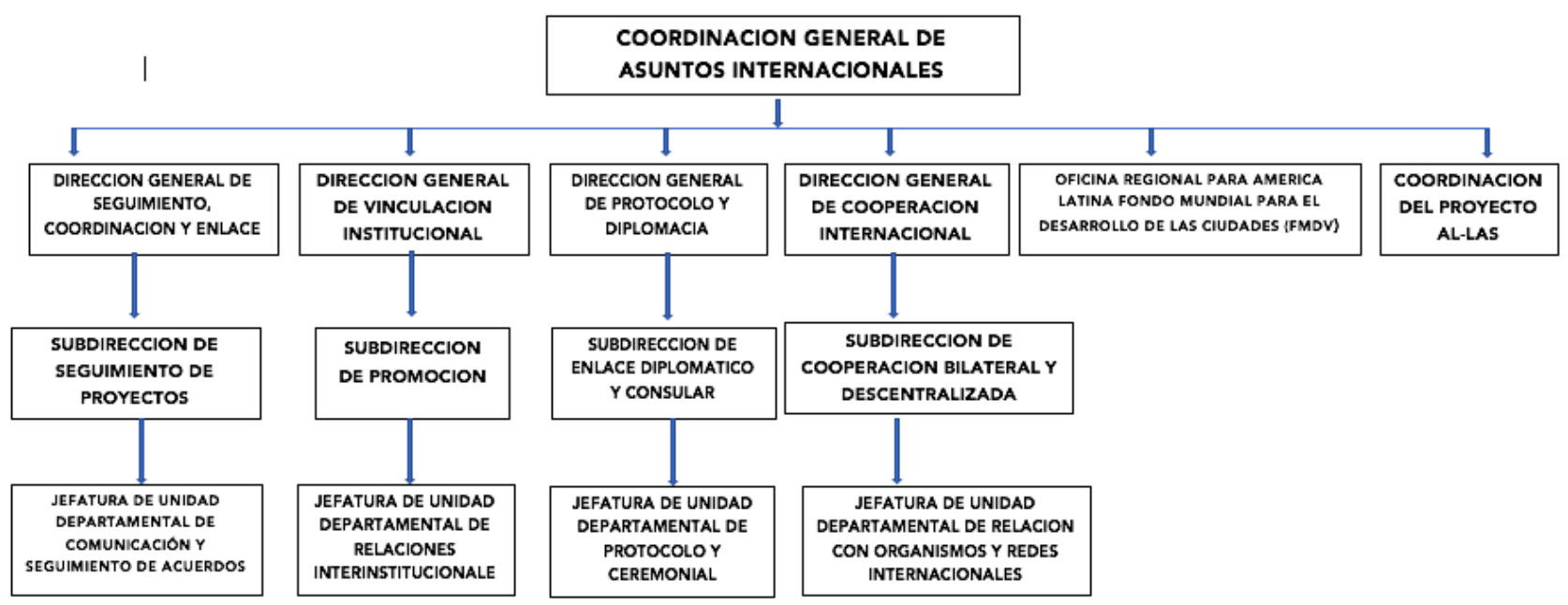

Fuente: Coordinación General de Asuntos Internacionales (CGAl), 2017

En todo caso, este contexto permite inferir que, a diferencia de CDMX, Bogotá ha contado durante mucho tiempo atrás con marcos jurídicos y legales que han garantizado la sostenibilidad del espacio organizacional de sus asuntos internacionales desde la Administración Distrital. Sin embargo, Ciudad de México ha tenido un perfil con mayores niveles de internacionalización hasta el punto de considerarse como una "ciudad 
global”. De acuerdo con Parnreiter (2002), este término hace referencia a ciudades que se convierten en nudos de la economía mundial, en los cuales se integran economías regionales, nacionales e internacionales a través del flujo de capitales, mercancías, migrantes, servicios financieros, entre otros. El atributo de ciudad global para CDMX se remonta a los años noventa cuando este mismo autor señaló que la Ciudad "se había convertido en parte de la red transfronteriza de las ciudades globales, las cuales constituyen la estructura básica de la economía mundial actual. Como parte de esta red, Ciudad de México asume funciones globales de la ciudad, como el control y la gestión de los servicios globalizados" (PARNREITER, 2000 apud LARA, 2015). Con el inicio del siglo XXI se buscó la inserción de la ciudad dentro de la categoría de ciudades globales (LARA, 2015), por lo que su vocación internacional no parece haber sido una consecuencia directa de los avances institucionales de los mandatarios de turno sino del proceso de globalización que la llevó a convertirse en parte activa de las redes donde se activa y estimula el sistema capitalista mediante el alto flujo de bienes y servicios, información, mercancías, etc.

Por último, lo que se puede observar es que la estructura organizacional de Bogotá y Ciudad de México ha venido cambiando y mostrando que la cooperación internacional ya no puede ser concebida como un instrumento asistencialista de relaciones Norte-Sur, soportado en la financiación de proyectos. Hoy en día, el perfil organizacional de las dos ciudades refleja un tipo de cooperación vinculado a los asuntos internacionales por lo cual, dentro de sus estructuras se contemplan una diversidad de temas y modalidades de gestión pública, acordes con las dinámicas relacionadas con el desarrollo internacional y las nuevas formas de gobernanza global.

Los planes y programas de desarrollo y los documentos de política

Otro factor común que permite explicar la institucionalización de la cooperación en Bogotá y CDMX está relacionado con la incorporación del tema en el plan de desarrollo de la administración de turno, considerado como el referente principal de planificación del desarrollo territorial en razón a que contiene el programa de gobierno que mandatario desarrollará durante su mandato.

Tanto Bogotá como Ciudad de México han incorporado de alguna manera los asuntos internacionales y de cooperación internacional dentro de sus planes o programas de desarrollo, mediante un eje independiente y estratégico dentro de la agenda pública o, en otros casos, como un componente transversal de las prioridades de gobierno.

Para el caso de Bogotá, las últimas tres administraciones finalizadas entre 2004 y 2015, incluyeron el tema a través de la integración internacional como un principio fundamental de la gestión pública y la cooperación internacional como una fuente de financiación (2004-2008), bajo un programa específico "Bogotá competitiva e internacional” (2008-2011) y como un Programa "Bogotá Humana Internacional" (2012-2015).

De igual manera, Ciudad de México incluyó el tema internacional y de cooperación como un tema de presencia internacional (2000-2006), como un componente transversal de los ejes estratégicos de la agenda 
política (2007-2012) y como un componente central y prioritario a través de un acápite específico en el que se plantea un enfoque de acción internacional para la ciudad.

Aunque esta es una dinámica comúnmente compartida, el contexto también demuestra que no existe una relación directa entre lo que se plantea en los planes o programas de desarrollo y una mayor o menor práctica de los asuntos internacionales. Así, por ejemplo, para el caso de Ciudad de México, el Programa General de Desarrollo del Distrito Federal 2000-2006 bajo la administración de Andrés López Obrador, resaltó la importancia de la presencia internacional para lo cual, se planteó una agenda que buscaba

fortalecer diversos vínculos de cooperación con sus contrapartes internacionales, tales como hermanamientos de ciudades, acuerdos de colaboración bilateral en materia científica, tecnológica, educativa, cultural, política, social y económica; así como con organismos multilaterales de países y ciudades con la finalidad de impulsar la realización de proyectos y generar una fuente alternativa de recursos (DISTRITO FEDERAL, 2001, p. 54).

Aun así, se considera que bajo esa administración las relaciones internacionales del gobierno de la CDMX perdieron dinamismo, que las actividades se limitaron a la recepción de huéspedes distinguidos y que se cancelaron y congelaron las giras al exterior y los acuerdos de cooperación internacional que estaban vigentes (CGAI , 2016).

Entonces, se podría afirmar que este factor de la institucionalización de los procesos de cooperación si bien demuestra el interés y la voluntad política del gobierno de turno frente a los asuntos internacionales y de cooperación, no necesariamente incide sobre la práctica de estos asuntos dentro de la gestión pública.

Ahora bien, junto a la estructura organizacional, la tendencia muestra como los documentos de política enmarcados en estrategias, planes o políticas públicas de cooperación internacional o internacionalización, se han convertido en elementos fundamentales de los procesos de institucionalización de la cooperación internacional que además contribuyen con una mayor legitimación en las relaciones con socios internacionales.

Lo interesante de estos documentos es que claramente demuestran las transformaciones de la cooperación internacional y terminan adaptándose y replicando los dictámenes del desarrollo y la ayuda internacional.

Al respecto, es posible identificar algunas diferencias entre las dos ciudades capitales. Durante el periodo 2007-2016, Bogotá demostró una gran apuesta de su internacionalización mediante la configuración de marcos estratégicos de cooperación internacional. En el 2007, bajo la administración de Luis Eduardo Garzón, el Distrito lanza la primera Estrategia de Cooperación Internacional de Bogotá, Distrito Capital (ECI), como resultado del trabajo de la Red Distrital de Cooperación para el Desarrollo.

En el año 2008, con la nueva administración de la ciudad en manos de Samuel Moreno, dicha estrategia fue actualizada, manteniendo las líneas prioritarias y temas transversales de la anterior y con ello, continuar con el proceso. Esta primera iniciativa institucional tuvo en cuenta las dinámicas del momento de ayuda al desarrollo, por lo cual, sus referentes interna- 
cionales y nacionales más cercanos fueron los Objetivos de Desarrollo del Milenio, la Declaración de París y el Proceso Londres-Cartagena- Bogotá.

Por su parte, la Estrategia de Cooperación Internacional de Bogotá 2012-2016, bajo la administración de Gustavo Petro, estuvo alineada con las nuevas dinámicas de la cooperación internacional, en la cual se buscaba promover una visión horizontal entre socios y aliados estratégicos, reconocer el papel cada vez más significativo de los gobiernos locales en la configuración de la agenda global, impulsar el intercambio de experiencias significativas de la Ciudad y las nuevas modalidades de cooperación mediante acuerdos city to city, la participación en redes internacionales y foros políticos y esquemas de cooperación sur - sur (ALCALDIA MAYOR DE BOGOTÁ, 2014).

A partir de estos derroteros, dicha estrategia planteó cuatro objetivos generales que buscaban consolidar los procesos de cooperación e internacionalización de Bogotá: 1. Posicionar a Bogotá D.C como actor influyente en procesos de cooperación descentralizada, 2. Aumentar la eficacia en los procesos de cooperación para el desarrollo de Bogotá, 3. Reafirmarse como un socio confiable y estratégico ante los socios y aliados estratégicos nacionales e internacionales, 4. Fortalecer el marco institucional para la ejecución de iniciativas y proyectos de cooperación.

Con la nueva administración de Bogotá (2016-2019) bajo el mandato del Alcalde Enrique Peñalosa, no se evidencian avances significativos que permitan definir un perfil de la cooperación internacional de la ciudad. Lo claro es que desde la Alcaldía hay una apuesta por la identificación e intercambio de buenas prácticas y la cooperación técnica. Así mismo, el gobierno distrital ha establecido algunos ejes estratégicos para la promoción de sus asuntos internacionales relacionados con el cambio climático, el desarrollo urbano, la seguridad, la movilidad sostenible, la cultura, entre otros.

Por otra parte, a partir del año 2006 Ciudad de México muestra una fuerte estrategia para posicionar la ciudad en el escenario internacional (CGAI, 2016). La apuesta se focaliza en un marco de internacionalización dentro del cual se encuentra la cooperación internacional como uno de sus componentes. En todo caso, la necesidad de un marco jurídico que le diera reconocimiento a la CGAI no permitió durante años la formulación de estrategias ni políticas públicas de cooperación internacional y/o internacionalización.

Por esa misma razón, se reconoce como un avance institucional significativo el haber formulado y vinculado el Programa Especial de Acción Internacional en el Programa General de Desarrollo del Distrito Federal (PGDDF) 2013-2018.

El PGDDF reconoce que la acción internacional no solo es una "política sectorial en sí misma, sino como un campo que permea, beneficia y enriquece de forma transversal a todas las actividades del gobierno local”. Para ello, establece tres criterios de orientación para CDMX, a saber: 1. Consolidar la presencia e influencia de la Ciudad de México como el núcleo de una megalópolis líder en América Latina y el mundo; 2. Posicionar a la Ciudad de México como un referente de sustentabilidad urbana e innovación, a través de intercambios de buenas prácticas y proyectos concretos de cooperación descentralizada; 3 . Incrementar el atractivo te- 
rritorial de la Ciudad de México como importante destino mundial del turismo, el capital humano, las artes, el comercio, los negocios y la inversión extranjera (GOBIERNO DE CIUDAD DE MÉXICO, 2016).

Como se puede observar en los dos casos de estudio, CDMX prefiere enmarcar sus acciones internacionales bajo la denominación de "asuntos internacionales", valiéndose de la cooperación como un componente más de su proceso de internacionalización. Por su parte, Bogotá ha querido darle un lugar a la cooperación internacional mediante la definición de estrategias específicas que guíen las acciones del gobierno de la ciudad. No obstante, ello, hay que destacar que en el Distrito existen otras instancias que apoyan el fortalecimiento de las relaciones internacionales de la ciudad con un tinte más económico y comercial como la Secretaría de Hacienda Distrital y la Agencia de Promoción de Inversión de Bogotá, Invest in Bogotá.

Dinámicas en los procesos de cooperación internacional

Frente a algunas modalidades utilizadas en los últimos años por las dos ciudades para promover sus asuntos internacionales, parece evidente que tanto Bogotá y Ciudad de México han seguido la lógica de promover la cooperación internacional como uno de los componentes de sus relaciones paradiplomáticas, sobrepasando el modelo tradicional del régimen de ayuda al desarrollo de tinte vertical y asistencialista y promoviendo nuevos esquemas que impulsan la relaciones entre socios, la participación en redes y la diplomacia de ciudades.

La siguiente gráfica da cuenta de algunas iniciativas vinculadas a los asuntos internacionales y a la cooperación, que permiten evidenciar el trabajo entre los años 2012 y 2015 de las dos ciudades capitales:

Gráfica No 1 Algunas actividades internacionales y de cooperación internacional de Bogotá y Ciudad de México (2012-2015)

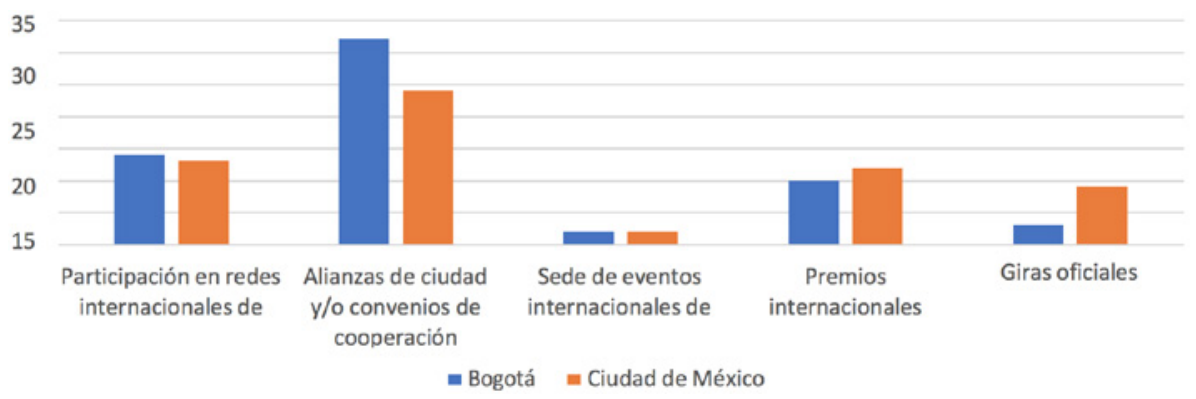

Fuente: elaboración propia con base en Gobierno del DF (2015) y Alcaldía Mayor de Bogotá (2015)

La gráfica muestra como las dos ciudades tienen similitudes en sus actividades internacionales. Sin embargo, en términos generales, llama la atención que CDMX tiene una apuesta más amplia de sus procesos y vincula con mayor fuerza dentro de sus asuntos internacionales temas como la colaboración con embajadas acreditada en México, las visitas oficiales a la ciudad y las giras internacionales del mandatario de turno desde las cuales surgen relaciones de cooperación más cercanas y duraderas. 
Así mismo, se puede evidenciar que las dos ciudades han adoptado un enfoque de tinte horizontal de sus relaciones de cooperación internacional traspasando el modelo tradicional de donante-receptor y relación norte-sur de la cooperación. Esto se demuestra, entre otras cosas, por los escasos recursos financieros que reciben estas ciudades y por las tendencias en la diversificación de socios y en una visión más estratégica de la cooperación internacional como un componente para participar activamente en redes internacionales de gobiernos locales, compartir e intercambiar experiencias y promover proyectos y programas de interés común entre ciudades de países en desarrollo.

Así, por ejemplo, para el caso de México, de los 24 convenios de cooperación internacional registrados entre 2012 y 2014, 10 de ellos fueron con América latina, 7 con Europa, 5 con Asia y 2 con América del Norte (GOBIERNO DEL DISTRITO FEDERAL, 2015). Esta misma tendencia se manifiesta en Bogotá a través de las alianzas establecidas en su mayoría con ciudades de América Latina, seguidas de ciudades europeas y asiáticas junto a alianzas con algunas agencias de cooperación y fondos y programas de Naciones Unidas.

Lo que se puede percibir entonces, es que las exigencias de la globalización junto a las transformaciones de la cooperación descentralizada y las prácticas recurrentes de los asuntos internacionales han ido más rápido y han terminado por permear los procesos institucionales para tal fin.

Consideraciones finales

En el marco de la globalización y el desarrollo internacional, los GNC han empezado a jugar un rol fundamental en la gestión y establecimiento de relaciones de cooperación internacional, con el propósito de aumentar su presencia en el escenario internacional y responder a los desafíos de la agenda internacional. En ese contexto, los nuevos esquemas de la COD se convierten en una oportunidad para que los GNC emprendan vínculos a través del intercambio de saberes y experiencias de desarrollo que fortalezcan la gestión pública y el desarrollo local. Para lograr este propósito, la práctica demuestra que estos gobiernos han apostado por espacios organizaciones junto a la definición de documentos de política con el propósito de ordenar, planificar y convertir la COD en un instrumento estratégico de sus relaciones internacionales.

Frente a esta situación, a partir de los dos casos de estudio, Bogotá y Ciudad de México, se pueden evidenciar algunas tendencias y prácticas comunes que permiten identificar algunos factores explicativos de los procesos de institucionalización de sus asuntos internacionales y de cooperación.

Estas dos ciudades capitales han venido apostándole a una institucionalización que permita vincular las acciones internacionales y la cooperación a la agenda pública local. Los avances en la materia se pueden reflejar en tres factores claramente identificados: la definición de un marco jurídico e institucional que formaliza y mantiene una estructura organizacional para los asuntos internacionales y de cooperación como parte del organigrama de la administración pública de las dos ciudades, 
la vinculación de los temas internacionales como ejes prioritarios o transversales en los planes de desarrollo, la definición de documentos de política y/o estrategias de internacionalización y cooperación y, el perfil de algunas dinámicas de los asuntos internacionales de las dos ciudades que muestra la tendencia a diversificar y sobrepasar la concepción tradicional del régimen internacional de ayuda al desarrollo, soportado en acciones asistencialistas y en financiación de proyectos a corto plazo.

Este último elemento cobra mayor importancia en la medida en que estos espacios institucionales y de gestión han venido adaptándose a las dinámicas del escenario internacional y en especial a los temas clave de la agenda del desarrollo apoyada en los Objetivos de Desarrollo Sostenible y en una mayor participación de los GNC en la gobernanza global.

No obstante, ello, parece claro que el marco jurídico y las estructuras organizacionales no garantizan por completo una mayor y mejor gestión de la cooperación internacional. Por tanto, otro factor fundamental que viene ligado a este aspecto está relacionado con los equipos de trabajo y la experticia que demuestran para una efectiva labor internacional. Este es uno de los principales desafíos que enfrenta las dos administraciones. De acuerdo con las entrevistas realizadas en los años 2016 y 2017, es común ver cómo, ante los cambios de gobierno y los intereses políticos, han existido altos niveles de rotación del personal, que no han permitido una efectiva sostenibilidad de los procesos.

De acuerdo con lo anterior, es claro reconocer que las dos ciudades capitales deben seguir apostando a la consolidación de internacionalización de "Ciudad-Capital-Global" y no a políticas enmarcadas en "gobiernos de turno", puesto que de esta forma se logrará garantizar la sostenibilidad de los procesos y su proyección, a partir de la definición de metas claras de corto, mediano y largo plazo que beneficien los procesos de desarrollo local.

Un último elemento a tener en cuenta en los avances de institucionalización tiene que ver con los mecanismos para una mejor coordinación y articulación con los diversos actores del desarrollo que inciden en cada una de las ciudades en los asuntos internacionales a efectos de no duplicar iniciativas y responder a los lineamientos y ejes estratégicos definidos por el territorio.

Al respecto, En el programa de acción internacional de CDMX se plantea que la internacionalización de la ciudad debe promover la inclusión de todos los actores y se conduce aunando esfuerzos con todos ellos (Gobierno de la Ciudad de México, 2016). Por su parte, la administración de Bogotá 2012-2015, reconoció la necesidad de promover la capacidad institucional de la alcaldía fortaleciendo los procesos de articulación, coordinación, toma de decisiones e intercambio de información (SDP, 2014). Para ello, quiso apostarle a un Sistema Distrital de Cooperación e Internacionalización de la ciudad, en el cual confluyeran todos los actores del sistema distrital, sectores, entidades adscritas centralizadas y descentralizadas y las alcaldías locales (SDP, 2014).

En todo caso, se podría decir que a pesar de las similitudes y diferencias en los procesos de institucionalización y de los factores explicativos en las dos ciudades capitales, no es tan claro el efecto de una mayor 
o menor institucionalización sobre la práctica de los asuntos internacionales y la cooperación. Lo que sí es claro, es que una mayor planificación permite una visión de mediano y largo plazo que terminará por beneficiar los procesos de desarrollo local de un territorio determinado, promoverá la sostenibilidad y continuará legitimando los procesos y generando mayor confianza con los socios internacionales.

Referencias

AGUIRRE, I. ¿Qué sentido tiene hablar de Paradiplomacia? Una encuesta intertextual en torno a un neologismo polisémico. En: ALDECOA, F.; KEATING, M. (Coords.). Paradiplomacia las relaciones internacionales de las regiones. Madrid: Marcial Pons. Cap. 10, p. 203-235. 2001

ALCALDÍA MAYOR DE BOGOTÁ. Acuerdo 257 de 2006 (30 de noviembre), por el cual se dictan normas básicas sobre la estructura, organización y funcionamiento de los organismos y de las entidades de Bogotá, Distrito Capital, y se expiden otras disposiciones. Registro distrital n. ${ }^{\circ}$ 3662. Bogotá. 2006. Disponible en: <http://www.alcaldiabogota.gov.co/sisjur/normas/Norma1.jsp?i=22307>. Acceso al 11 nov. 2017.

ALCALDÍA MAYOR DE BOGOTÁ. Balance en cifras y logros destacados. Bogotá. 2014.

ALCALDÍA MAYOR DE BOGOTÁ. Decreto 163 de 2008 (11 de junio), por el cual se modifica parcialmente la estructura organizacional y funcional de la Secretaría General de la Alcaldía Mayor de Bogotá, D.C. y algunas funciones de la Secretaría Distrital de Planeación. Registro distrital n. ${ }^{\circ}$ 3997. Bogotá, 2008. Disponible en: <http://www.alcaldiabogota.gov.co/sisjur/normas/Norma1.jsp?i=30740>. Acceso al 6 dic. 2017.

ALCALDÍA MAYOR DE BOGOTÁ. Decreto 425 de 2016 (3 de octubre), por medio del cual se modifica la Estructura Organizacional de la Secretaría General de la Alcaldía Mayor de Bogotá D.C. 2016

ALCALDÍA MAYOR DE BOGOTÁ. Decreto 550 de 2006 (29 de diciembre), por el cual se adopta la estructura interna de la Secretaría de Planeación de la Alcaldía Mayor de Bogotá DC. y se dictan otras disposiciones. Bogotá, 2006. Disponible en: <http://www.alcaldiabogota.gov. co/sisjur/normas/Norma1.jsp?i=22568>. Acceso al 6 dic. 2017.

ALCALDÍA MAYOR DE BOGOTÁ. Estrategia de Cooperación Internacional de Bogotá 2012 - 2016. Bogotá. 2014.

ALCALDÍA MAYOR DE BOGOTÁ. Plan de desarrollo de Bogotá 2004-2008. Bogotá Sin Indiferencia un Compromiso Social Contra la Pobreza y la Exclusión. 2004.

ALCALDÍA MAYOR DE BOGOTÁ. Plan de desarrollo de Bogotá 2008-2011. Bogotá Positiva: Para Vivir Mejor. 2008

ALCALDÍA MAYOR DE BOGOTÁ. Plan de desarrollo de Bogotá 2012-2015. Bogotá Humana. 2012.

ALCALDÍA MAYOR DE BOGOTÁ. Secretaría de planeación. Balance de la política de integración regional e internacional de Bogotá 2001 - 2007. Bogotá. 2007.

ALCALDÍA MAYOR DE BOGOTÁ. Secretaría de planeación. Integración regional y cooperación. Avances, logros y retos 2008 - 2011. Bogotá. 2011.

APC-Colombia. Mapa de cooperación internacional. 2013. Disponible en: $<$ http://190.248.17.195:8000/mapacooperacion/apcNew2.3/>. Acceso al 15 marzo. 2016.

COLOMBIA. Constitución (1991). Constitución Política de Colombia.

COORDINACIÓN GENERAL DE ASUNTOS INTERNACIONALES DE LA JEFATURA DE GOBIERNO DE LA CIUDAD DE MÉXICO. La Ciudad de México en el mundo. Hacia una política pública de acción internacional. Ciudad de México: CGAIX. 2016.

COORDINACIÓN GENERAL DE ASUNTOS INTERNACIONALES DE LA JEFATURA DE GOBIERNO DE LA CIUDAD DE MÉXICO. Ciudad de México internacional 2012-2015. Ciudad de México: CGAIX. 2017.

CORNAGO, N. La descentralización como elemento de innovación diplomatica: aproximación a sus causas estructurales y lógicas de acción. En: MAIRA, L. (Ed.). La política internacional subnacional en América Latina. Buenos Aires: El Zorzal. Cap. 3, p. 107-134. 2010. 
DÍAZ, A. La cooperación descentralizada pública en México: La hora ha llegado. Montevideo: Observatorio de Cooperación Descentralizada UE-AL, 2007.

DÍAZ, A. La cooperación oficial descentralizada. Cambio y resistencia en las relaciones internacionales contemporáneas. Madrid: Catarata. 2008.

DIMAGGIO, P; Powell, W. Retorno a la jaula de hierro: el isomorfismo institucional y la racionalidad colectiva en los campos organizacionales En: DIMAGGIO, P.; POWELL, W. (Comps.). El nuevo institucionalismo en el análisis organizacional. México: Fondo de Cultura Económica, p.104-125. 1999.

DUCHACEK, I. (1984). The International Dimension of Subnational Self-Government. Publius, Oxford, v. 14, n. 4, p. 5-31. 1984. Disponible en: <https://www.jstor.org/stable/3330188?seq=1\#page_scan_tab_contents $>$. Acceso al 31 enero. 2018.

FEJERSKOV, A. Understanding the nature of change: how institutional perspectives can inform contemporary studies of development cooperation. Journal Third World Quarterly, V. 37 - 12. DOI: 10.1080/01436597.2016.1159128, Routledge, 2016. Disponible en: <https://www. tandfonline.com/doi/abs/10.1080/01436597.2016.1159128>. Acceso al 11 nov. 2017.

GOBIERNO DE CIUDAD DE MÉXICO. Constitución Política de los Estados Unidos Mexicanos. 2016.

GOBIERNO DE CIUDAD DE MÉXICO. Programa Especial de Acción Internacional. 2016. GOBIERNO DE LA FEDERACIÓN. Constitución Política de los Estados Unidos Mexicanos. 1917.

GOBIERNO DEL DISTRITO FEDERAL. Programa General de Desarrollo del Distrito Federal 2002-2006. 2001.

GOBIERNO DEL DISTRITO FEDERAL. Programa General de Desarrollo del Distrito Federal 2007-2012. 2007.

GOBIERNO DEL DISTRITO FEDERAL. Programa General de Desarrollo del Distrito Federal 2013-2018. 2013.

GRANDAS, D.; PRADO, JP (2017). La cooperación internacional descentralizada en Colombia. Un análisis institucionalista sobre el departamento de Cundinamarca. Revista Oasis, Bogotá, 25, p. 159-186. 2017.

HOCKING, B. Localizing Foreign Policy. Non Central Governments and Multilayered Diplomacy. 1. ed. New York: Palgrave Macmillan. 1993.

JACKSON, R.; SORENSEN, G. Introduction to International Relations. Theories and Approaches. Oxford: Oxford University Press. 2010.

JEFFERY, C. Recasting German Federalism: The legacies of unification. London, New York: Pinter Publishers. 1999.

KEOHANE R.; NYE J. Transnational Relations and World Politics. Cambridge, MA: Harvard University Press. 1973.

KEOHANE, R. After Hegemony: Discord and Cooperation in the World Political Economy. Princeton: Princeton University Press. 1984.

KeOHANE, R.; NYE, J. Poder e Interdependencia. La política mundial en transición. 1. ed. Buenos Aires: Grupo Editor Latinoamericano. 1989.

KEOHANE, R.; NYE, J. Power and interdependence. 4. ed. Estados Unidos: Pearson Education. 2011.

KINKAID, J. Constituent Diplomacy in Federal Polities and the Nation-State: Conflict and Co-operation. En: MICHELMANN, H.; SOLDATOS P. (Coords). Federalism and International Relations: The Role of Subnational Units. Oxford: Oxford University Press. Cap. 3, p. 54-75. 1990.

KRASNER, S. Soberanía: hipocresía organizada. Barcelona: Editorial Paidos. 2001.

KRASNER, S. Structural Causes and Regime Consequences: Regimes as Intervening Variables. International Organization Journal, v. 36, n. 2, p. 185-205. 1982.

KUZNETSOV, A. Theory and practice of paradiplomacy: subnational governments in international affairs. London; New York: Routledge. 2015.

LARA, R. La construcción de ciudades modelo y su inserción internacional los casos de ciudad de México, Singapur y Bilbao. 2015. 617 f. Tesis (doctorado)- Programa de Doctorado en Estudios Internacionales, Universidad del País Vasco, Donostia, 2015. 
LASCURAIN, M.; LÓPEZ, J.A. Retos y oportunidades de la globalización económica. Confines de Relaciones Internacionales y Ciencia Política, Nuevo León, v. 9, n. 17, p. 9-34. Universidad TecnológicodeMonterrey. 2013. Disponible en: <http://www.scielo.org.mx/pdf/confines/ v9n17/v9n17a1.pdf>. Acceso al 31 enero. 2017.

MARTÍNEZ, I.; SANAHUJA, J. La agenda internacional de eficacia de la ayuda y la cooperación descentralizada. España. Madrid: Fundación Carolina, 2009.

MARTÍNEZ, I.; SANAHUJA, J. La cooperación descentralizada española y la eficacia de la ayuda: los desafíos de la complementariedad y la división del trabajo. En: MARTÍNEZ, I.; SANAHUJA, J. (Coords). Eficacia de la ayuda y división del trabajo: Retos para la cooperación descentralizada española. Madrid: Ceipaz, Cap. 1, p.11-27. 2012.

MEYER, J.; \& ROWAN, B. Organizaciones institucionalizadas: la estructura formal como mito y ceremonia. En: DIMAGGIO, P.; POWELL, W. (Comps.). El nuevo institucionalismo en el análisis organizacional. México: Fondo de Cultura Económica, p. 70-103. 1999

MILANI, C.; RIBEIRO, M. Paradiplomacia y acción internacional de las ciudades brasileñas: la elaboración del concepto de gestión internacional local. Geopolítica(s). Revista de estudios sobre espacio y poder, v. 1, n. 1, p. 23-40. 2010.

PARNREITER, C. Ciudad de México: el camino hacia una ciudad global. EURE, v. 28, n. 85, p. 89-119. 2002. Disponible en: <https://dx.doi.org/10.4067/S0250-71612002008500006>. Acceso al 30 de septiembre. 2018

PRADO, JP.; OCHOA, L. Cosmopolitismo, constructivismo y liberalismo institucional: diálogo teórico en torno a la cooperación internacional para el desarrollo. Araucaria, Revista Iberoamericana de Filosofía, Política y Humanidades, año 19, n. 37, p. 273-299. 2017. Disponible en: <https://revistascientificas.us.es/index.php/araucaria/article/view/3496/2934>. Acceso al 25 marzo. 2018.

PROGRAMA DE LAS NACIONES UNIDAS PARA EL DESARROLLO (PNUD). Medición de la eficacia de la cooperación al desarrollo a nivel local-Ecuador. 2013. Disponible en: $<$ http:// www.undp.org/content/dam/ecuador/docs/2013\%20ART_Medici\%C3\%B3n\%20de\%201a\%20eficacia\%20de\%20la\%20cooperaci\%C3\%B3n\%20a\%20nivel\%20local_2.pdf.> Acceso al 15 abr. 2016.

ROBLEDO, P. La autonomía municipal en Colombia. Colombia. Bogotá: Universidad Externado de Colombia, 2010.

SALOMÓN, M. (2012). Em que medida é possível integrar a Cooperação Descentralizada na dimensão Sul-Sul da política externa brasileira?. Revista Mural Internacional, Rio de Janeiro. v. 3, n. 2, p. 9-15. 2012.

SANAHUJA, J. Del interés nacional a la ciudadanía global: la ayuda al desarrollo y las transformaciones de la ciudadanía global. En: SANAHUJA, J.; GÓMEZ, M. (Eds.). La cooperación al desarrollo en un mundo en cambio. Madrid: Cideal, Cap 2, p. 53-123. 2001.

SCHIAVON, J. La diplomacia local en los gobiernos estatales en México. (2010-2010). México, CIDE, 2010

SECRETARÍA DISTRITAL DE PLANEACIÓN. Sistema de información para la cooperación. Bogotá. 2007.

SOLDATOS, P. An Explanatory Framework for the Study of Federated States as Foreign-policy Actors. En: MICHELMANN H.; SOLDATOS P. (Coords). Federalism and International Relations: The Role of Subnational Units. Oxford: Oxford University Press, Cap. 2, p. 34- 53. 1990.

ZAMORA, E. Bogotá, Cali y Medellín en el escenario internacional (2001- 2012). Revista Desafios, Bogotá, v. 28, n. 1, 2016. p. 247-293.

ZUBELZÚ, G. El diseño institucional y los perfiles de gestión externa de las provincias argentinas. En: IGLESIAS, E.; IGLESIAS, V.; ZUBELZÚ, G. Las provincias argentinas en el escenario internacional. Desafíos y obstáculos de un sistema federal. Buenos Aires: CARI-PNUD, Cap. 3, p. 83-106. 2008. 